\title{
Danto’s Dialectic
}

\author{
Adrian Haddock
}

University of Stirling

1. I would like to begin with a passage from Immanuel Kant's essay "The Idea of a Universal History from a Cosmopolitical Point of View”.

[It] may be hoped that when the play of the freedom of the human will is examined on the great scale of universal history, a regular march may be discovered in its movements, and that, in this way, what appears to be tangled in the case of individuals, will be recognised in the history of the whole species as a continually advancing, though slow, development of its original capacities and endowments ... We will accordingly see whether we can succeed in finding a clue to such a history; and in the event of doing so, we will leave it to nature to bring forth the man who will compose it. Thus did she bring forth a Kepler who, in an eccentric way, reduced the definite paths of the planets to definite laws; and then she brought forth a Newton, who explained these laws by a universal natural cause. ${ }^{1}$

Here we have the vision of a person who will write what Arthur C. Danto calls a substantive philosophy of history. A central aim of Danto’s Analytical Philosophy of History is to show that it is not possible for such a person ever to come forth.

Kant may be one of Danto's targets, but, as Danto is well aware, there is something palpably Kantian about his own enterprise. Just as the Transcendental Aesthetic and Analytic are supposed to state the conditions that make a priori knowledge possible, and the Transcendental Dialectic to show, in Danto’s words, “the unhappy destiny which attends Reason when it attempts to extend [the] forms of understanding

\footnotetext{
${ }^{1}$ Trans. W. Hastie, in P. Gardiner (ed.) Theories of History (Glencoe: Free Press, 1959), p. 23. Cited in Arthur C. Danto, Narration and Knowledge $3^{\text {rd }}$ edition, including the integral text of Analytical Philosophy of History [1968] (New York: Columbia University Press, 2007), p. 3-4.
} 
specified in the Analytic beyond"² those conditions, so Analytical Philosophy of History is supposed to state the conditions that make ordinary historical knowledge possible, and to show "the unhappy destiny" that attends the substantive philosophy of history when it attempts to extend modes of representation beyond those conditions. So, it comes as no surprise when Danto says that it is "in the spirit of critical philosophy" ${ }^{3}$ that he wishes his argument to be understood.

The aim of this paper is to offer an assessment of - what we might call - Danto's Dialectic: his attempt to show that the idea of a substantive philosophy of history is the incoherent - idea of a form of historical knowledge that violates its own conditions of possibility. My assessment will not be wholly positive. But I hope it will bring to light aspects of Danto's thinking that have been the objects of undeserved neglect.

2. Analytical Philosophy of History was published in 1968, and it does tend to show its philosophical age. Its concern may be historical knowledge and its limits, but, as befits its time of writing, it masks that concern by continual semantic ascent, talking rarely of knowledge or even representation, and continually of 'sentences', true and otherwise. But knowledge and representation are its concern, ${ }^{4}$ and its ambition is Kantian: to show that the very conditions that sceptically-minded philosophers treat as fetters on, or even as barriers to, historical knowledge, are the very conditions that make such knowledge possible. ${ }^{5}$

It ought to be uncontroversial that historians attempt to acquire knowledge of the past. But, we might think, this is just to say that historians attempt to acquire knowledge of certain propositions, viz. propositions about events that happen to take place at a time

\footnotetext{
${ }^{2}$ Danto, Narration and Knowledge, p. 257.

${ }^{3}$ Danto, Narration and Knowledge, p. 257.

${ }^{4}$ Danto now thinks of his earlier talk of "narrative sentences” as a kind of joke, and makes clear that his concern was always historical representation and historical knowledge. See his 'Response to Ankersmit' in D. Herwitz and M. Kelly (eds.) Action, Art, History: Engagements with Arthur C. Danto (New York: Columbia University Press, 2007).

${ }^{5}$ The conditions in question are conditions on something's so much as being a possible instance of knowledge of a certain sort. It is possible for something to meet the conditions but not be an actual instance of knowledge of this sort. But it is not possible for something to be an actual or possible instance of knowledge of this sort but not meet the conditions. Conditions of this sort are examined in detail in Henry E. Allison, Kant's Transcendental Idealism: An Interpretation and Defense, revised and enlarged edn. (New Haven: Yale University Press, 2004).
} 
anterior to that at which the historians attempt to acquire their knowledge. Put like that, historians seem to be at an epistemic disadvantage. How much better it would be if their attempt to acquire their knowledge could take place at the very same time as the events about which they are attempting to know! Then they could make use of a genuinely reliable source of information: they could actually witness the events, as they happen, rather than relying on the necessarily unreliable sources that constitute their ordinary stock-in-trade.

In this line of thought, the fact that historians' standpoint is future to the putative objects of their knowledge places a limitation on their epistemic capacity. Perhaps the fact that historians have such a standpoint constitutes a barrier to historical knowledge: they cannot acquire knowledge of the relevant propositions, because the only way for them to do so would be to do what they cannot do, and witness the relevant events, as they happen. Or perhaps the fact constitutes a fetter on historical knowledge: they can only acquire knowledge of those relevant propositions that are couched at a suitably high level of abstraction $-<$ Henry VII lived sometime before the start of the $17^{\text {th }}$ century $>$ for example, but not $<$ on the $22^{\text {nd }}$ August 1485, Henry VII was victorious at the Battle of Bosworth Field $>$ - because the only way for historians to acquire knowledge of relevant propositions at lower levels would be to do what they cannot do, and witness the relevant events, as they happen.

Danto's Kantian aim is to turn the game played by the sceptic against itself, by showing that it is, neither a fetter on, nor a barrier to, but a condition of the possibility of historical knowledge that it is acquired from a standpoint future to the events it concerns. Historical knowledge can only be acquired from this standpoint. Witnessing is of no help.

In line with the spirit of his philosophical age, Danto introduces the idea of historical knowledge by reference to the kind of sentences that may be used to express it; what he calls narrative sentences, and characterises as follows.

[The] most general characteristic [of narrative sentences] is that they refer to at least two time-separated events though they only describe (are only about) the earliest event to which they refer. Commonly they take the past tense, and indeed it 
would be odd ... for them to take any other tense. The fact that these sentences may constitute in some measure a differentiating stylistic feature of narrative writing is of less interest to me than the fact that use of them suggests a differentiating feature of historical knowledge. ${ }^{6}$

'Thatcher's decision to withdraw the warship Endurance from the South Atlantic precipitated Argentina's invasion of the Falkland Islands' would be an example of a narrative sentence. But Danto insists that narrative sentences form a very wide class, whose members include, inter alia, every sentence that can be used to speak of causal relations. So, 'the striking of the match caused the lighting of the match' would be another example. The central mark of narrative sentences is that they are true only if the later of the two events to which they refer (the Falklands War; the lighting of the match) actually takes place. In consequence, the proposition expressible by such a sentence cannot be known simply by witnessing the event that it is about - in Danto's somewhat technical sense of 'about' - because knowing such a proposition requires knowing what happens in the future of such an event. That is what it means to say that historians can only acquire historical knowledge from a standpoint future to the events about which they attempt to know.

So-called scepticism about historical knowledge is not, then, scepticism about historical knowledge at all, but scepticism about some other sort of knowledge, precisely because the sort of knowledge that this scepticism denies the historian can be acquired from somewhere other than the historian's standpoint, viz. from the standpoint of someone who simply witnesses the relevant events, as they happen. If scepticism about this other kind of knowledge is a problem for critical philosophy, it is not, Danto contends, a problem for the critical philosophy of history in particular.

3. Danto sharpens the idea of historical knowledge by way of the fantasy of the Ideal Witness, who is "capable of seeing all at once everything that happens, as it

\footnotetext{
${ }^{6}$ Danto, Narration and Knowledge, p. 143.
} 
happens, the way it happens". 7 Danto's point is that even though the Witness may be ideal qua witness, she is far from ideal qua historian, precisely because she lacks “knowledge of the future”. Danto invites us to imagine a chronicle set down by the Ideal Witness "of everything that happens across the whole forward rim of the Past" . (Here we are to imagine the Past as "a great sort of container ... which grows moment by moment longer in the forward direction” ${ }^{9}$ as time passes.) Danto does not deny that this Ideal Chronicle can be of help to the historian. But he thinks it is insufficient to yield historical knowledge of the events that form the historian's concern.

I would like to raise a question about the extent to which the Ideal Chronicle can be of help to the historian. Doing so will enable me to bring into focus one of Danto's most important, and most neglected, contributions, not only to the philosophy of history, but also to the philosophy of action. ${ }^{10}$

It seems that the invocation of the Ideal Chronicle misfires. Danto seems to assume that each narrative sentence is about an event mentioned in the Chronicle, but refers to an event in the future of this event that is not mentioned in the Chronicle. But although that is possible, it is not necessary. A narrative sentence might be about an event mentioned in the Chronicle, and refer to an event in its future that is also mentioned in the Chronicle. We might put the point by saying that it is not true that the Chronicle does not contain knowledge of the future if the future in question is the future of almost all the events the figure in the Chronicle. The only events of whose future the Chronicle is ignorant are - as it were - those located on the Past's forward rim. And there is no reason to think that every narrative sentence must refer to an event beyond that rim. So, we have as yet no reason to think the Chronicle cannot provide a basis for claims made by means of narrative sentences, and in that way yield historical knowledge.

However, it remains the case that there are no narrative sentences in the Ideal Chronicle itself. And that leads Danto to ask whether the Chronicle is so much as able to contain descriptions of events of the sort that interest the historian. That is a pressing

\footnotetext{
${ }^{7}$ Danto, Narration and Knowledge, p. 151. Danto sometimes talks of an Ideal Chronicler (for reasons that will shortly become clear). But the crucial thing about the Ideal Chronicler is that he is - merely - an ideal witness.

${ }^{8}$ Danto, Narration and Knowledge, p. 149.

${ }^{9}$ Danto, Narration and Knowledge, p. 146.

${ }^{10}$ Danto's other contributions to the philosophy of action are to be found in his Analytical Philosophy of Action (Cambridge: Cambridge University Press, 1973).
} 
question, for two reasons. First, if it is unable to do so, the Ideal Chronicle promises to be of no real help to the historian. Second, it looks as if it is a very real possibility that it is unable to do so, as Danto notes.

Narrative sentences refer to at least two time-separated events, and describe the earlier event. But in a sense this structure is exhibited in a whole class of sentences used to describe actions. $^{11}$

And actions are surely events of a sort that interest historians.

'NN rang the bell' seems to be a representative example of a sentence that can be used to describe actions. It also seems to be an example of a sentence that exhibits the structure Danto has in mind. The following seems to be true of this sentence. First, its truth turns on the occurrence of a particular event, viz. a ringing of the bell; an event to which it may thereby be said to refer. Second, its truth also turns on whether this particular event causes an event in its future, viz. the bell's ringing; an event to which it may thereby also be said to refer. ${ }^{12}$ So, it seems as if its truth turns on whether the earlier of the two events to which it refers causes the later of the two events. ${ }^{13}$ In other words, it seems as if it is a - covert - narrative sentence, and, as such, excluded from the Ideal Chronicle. Must every sentence suitable for describing action suffer this fate?

Danto thinks not. He thinks that at least some actions can be described by nonnarrative sentences. He reasons as follows.

'NN rang the bell' says what NN has done. But 'NN is ringing the bell' says what NN is doing. And it is possible to say truly that someone is doing something even though it is not, and will not be, possible to say truly that she has done it. ' $\mathrm{NN}$ is ringing a bell' seems not to exhibit this structure. But consider a sentence describing a more creative,

\footnotetext{
${ }^{11}$ Danto, Narration and Knowledge, p. 159.

${ }^{12}$ Of course this is not an uncontroversial notion of reference. But it seems as if the position under discussion needs it, or something like it, if it is to make good on its claim that sentences descriptive of action are narrative sentences.

${ }^{13}$ No doubt it is an analytic truth that if there is a ringing of the bell then there is the bell's ringing. But Davidson has taught us that that is no obstacle to the first's event's being a cause of the second. And his case seems to turn on the fact that the former event satisfies at least one another description that cannot be pressed into such a truth; 'a pulling of the cord', for example. (It may be true that if there is a pulling of the cord then there is a ringing of the bell. But it cannot be an analytic truth.) See Donald Davidson, 'Actions, Reasons, and Causes' (1963), in his Essays on Actions and Events (Oxford: Oxford University Press, 2001).
} 
less punctuate, exercise of agency - 'NN is writing a book', or 'NN is baking a cake'; a sentence in the so-called present progressive tense. It may be true to say that $\mathrm{NN}$ is writing a book, even though no particular book emerges as a result of her writing (perhaps because she suffers writer's block at some point in the writing process).

Exercises of agency are not special in this regard: it may be true to say of a tree that it is falling to the ground even though the tree does not fall to the ground (perhaps because someone catches it at some point in the falling process).

We might try to understand sentences such as 'NN is writing a book' on the model of sentences such as 'NN rang the bell'. But if we do we need to ask: what is the event that ' $\mathrm{NN}$ is writing a book' describes, and what is the particular event in its future that it causes? Perhaps we can say that the former is: a writing of a book. But are we to speak of the event of a book's being written in order to capture the latter - as if events can consist simply in something's instantiating a certain property $?^{14}$ Or are we to insist that events must involve changes in the properties of things, and proceed to describe the latter event by speaking of a book's getting, or becoming, written?

Each suggestion looks hopeless in the light of the phenomenon we have just noted. A thing can be the subject of a particular event only if the thing in question is, or perhaps has been, in existence. So, there can be a particular event whose subject is a book only if the book in question is, or perhaps has been, in existence. And so, to say that the truth of ' $\mathrm{NN}$ is writing a book' turns on the occurrence of an event whose subject is a book is to say that its truth turns on the existence of a particular book. But, as we have seen, its truth does not turn on the existence of a particular book. So, the model breaks down at this point. And with its demise goes the demise of our attempt to press every description of action into the form of a narrative sentence. Or so Danto assumes.

It seems to me that Danto makes a persuasive case for his claim that not all sentences descriptive of action are narrative sentences. But it does not follow that the Ideal Chronicle is thereby shown to be an aid to help historians. And this is because the worry that the Chronicle lacks the resources to describe action remains.

\footnotetext{
${ }^{14}$ Of course some philosophers once thought they could so consist. For a good overview and critique of the relevant literature, see Helen Steward, The Ontology of Mind: Events, Processes, and States (Oxford:

Oxford University Press, 2007).
} 
In this paper, I have spoken of events such as a ringing of the bell. I have also said such things as: NN is ringing a bell. We may surely say that both of these ways of speaking are ways of describing action. But it is not clear that they are equivalent. The following has been suggested: just as it can be true that NN is writing a book without it being true that there is a book $\underline{b}$ such that $\mathrm{NN}$ wrote $\underline{\mathrm{b}}$, so it can be true that $\mathrm{NN}$ is writing a book without it being true that there is an action - in the sense of a particular event - of writing a book a such that NN engaged in $\underline{\text { a. }}$ Of course, if NN is writing a book then NN is executing an action of writing a book. But just as it does not follow from this that there is a particular book such that NN has written that, so it does not follow that there is a particular action of writing a book such that NN has executed that. One can be writing a book even though a particular book does not emerge from the process. In the same way, one can be executing an action even though a particular action does not emerge from the process. As we might put it: just as books do not enter the world until they are completed (viz. written), so actions do not enter the world until they are completed (viz. executed).

I cannot pretend that this argument is conclusive. ${ }^{15}$ But it is at least suggestive, and if it is sound it shows that there are at least some descriptions of action - some descriptions to the effect that someone is doing something - that do not refer to a particular event. There are, as it were, some descriptions of action in execution that are not descriptions of executed actions. So, we may say that, if the argument is sound, then there are some descriptions of action that cannot figure in the Ideal Chronicle - not because the Chronicle cannot make use of narrative sentences, but because it can only make use of sentences that describe particular events. And yet, it seems it cannot make use of sentences that describe particular events where these events are actions, precisely because such sentences - sentences such as 'NN wrote the book', and 'NN rang the bell' - are, surely, narrative sentences (of the sort exposed seven paragraphs back).

The upshot is that the Chronicle cannot contain sentences descriptive of action. The irony is that the very sentences that Danto hoped could save the Chronicle from

\footnotetext{
${ }^{15}$ It is not my argument; it is Michael Thompson’s. See his 'Naïve Action Theory', in his Life and Form (forthcoming). Thompson's paper is but one of a number of recent attempts to come to terms with the significance of the progressive for our thinking about action. Other examples include: Kevin Falvey, ‘Knowledge in Intention’, Philosophical Studies, vol. 99, no. 1 (2000), pp. 21-44; and John McDowell, 'Intention in Action', Howison Lecture U.C. Berkeley (2006). Each of these philosophers is following a path that Danto traced for us back in 1968.
} 
being of no use to historians - viz. sentences in the progressive - serve, if this argument is right, not to save the Chronicle from being useless, but to secure its uselessness, in the present regard.

Even though I have sought to question one of Danto's assumptions regarding the Ideal Chronicle, I hope it is clear that my way of doing so emerges from his own pathbreaking, and insufficiently appreciated, emphasis on the significance of the progressive. I have passed over many of the interesting things Danto has to say on this matter, and only focussed on those aspects of his writings on the progressive that shed light on our central topic; viz. the scope and significance of narrative sentences for our understanding of historical knowledge.

4. The point of Danto's characterisation of historical knowledge in terms of narrative sentences is to provide a foundation for his attack on the possibility of historical foreknowledge - the putative historical knowledge that substantive philosophers of history take themselves to unearth.

As we have seen, Danto thinks it a condition of the possibility of historical knowledge that it is acquired from a standpoint future to the event it is about (in Danto's somewhat technical sense of 'about'; see §2). But, according to Danto, the idea of historical foreknowledge is the idea of historical knowledge that is acquired from a standpoint prior to the event it is about. And that makes it tempting to conclude that historical foreknowledge is impossible, precisely because the very idea of such knowledge is the idea of historical knowledge shorn of one of its conditions of possibility.

But that conclusion rests on a slide between two different senses of 'standpoint'. To say that historical knowledge can only be acquired from a future standpoint might be to say that it must involve knowledge of what happens in the future of the event it is about. But it might also be to say that it can only acquired by someone whose present historical location is in the future of the event it is about. The proponent of historical foreknowledge acknowledges the need for the future standpoint in the first sense. But she denies the need for the future standpoint in the second sense. To have a case against 
the substantive philosophy of history, Danto needs to establish that historical foreknowledge demands a future standpoint not only in the first sense, but in the second sense as well. And for that a new argument is needed.

As far as I can see, Danto thinks he has not one, but two arguments which establish this conclusion.

5. The first argument is simple to describe, but hard to accept.

According to Danto, the assumption that historical foreknowledge is possible is inconsistent with "our common way of viewing time, truth, and the world". ${ }^{16}$ Consider some arbitrary person who possesses putative historical foreknowledge that P. Two things are true of this person. First, the proposition that forms the content of her putative historical knowledge refers to an event future to the event it is about. Second, both this future event and the event the proposition is about are future to the present historical location of the person in question. But according to what Danto considers "our common way of viewing time, truth, and the world”, a proposition that makes reference to something future to the present historical location of the person who entertains the proposition cannot be true. So, the propositional content of the person's putative historical foreknowledge that $\mathrm{P}$ cannot be true. But someone knows that $\mathrm{P}$ only if $\mathrm{P}$ is true. So, the person cannot possess historical foreknowledge that P. It follows that historical foreknowledge is impossible, because there is nothing special about the person in question.

That is a striking argument. At its heart is the claim that future-referring propositions cannot be true. Danto does not so much argue for this claim as commend it to us as part of "our common way of viewing time, truth, and the world”. His commendation rests on the assumption that there are not simply tensed sentences but also tensed propositions. Past-referring propositions in the past tense, and present-referring propositions in the present tense, can be true or false. <Argentina are invading the Falkland Islands> is true when the invasion is happening, and false at any other time. $<$ Argentina invaded the Falkland Islands > is true when the invasion has happened, and

\footnotetext{
${ }^{16}$ Danto, Narration and Knowledge, p. 194.
} 
false at any other time. But future-referring propositions in the future tense cannot be true. < Argentina will invade the Falkland Islands> is false when the invasion has happened or is happening, and neither true nor false at any other time.

Danto's assumption that propositions are tensed is highly controversial. Some sentences are tensed, of course. ${ }^{17}$ But - we might think - propositions themselves are tense-free, even when they are expressed by tensed sentences. The future tense sentence 'Argentina will invade the Falkland Islands', uttered on the $10^{\text {th }}$ December 1980 expresses the tense-free proposition < Argentina invades the Falkland Islands at some time after $10^{\text {th }}$ December 1980>, for example. Short of that assumption - for which Danto does not argue - it is not open to us to think that future-referring propositions are in the future tense, and so as yet not closed to us to think that future-referring propositions can be true.

Danto's first argument is, then, at best incomplete. But this need not matter, because Danto has another argument against the possibility of historical foreknowledge which is indifferent to the supposedly tensed character of future-referring propositions.

6. The second argument is also easy to describe. And it is reasonably easy to accept - when suitably reconstructed. We have historical foreknowledge only if we "know what the historians of the future are going to say"18. But we do not know what the historians of the future are going to say. Therefore, we do not have historical foreknowledge.

The propositional contents of historical knowledge - what we might call historical propositions - are expressed in true narrative sentences. But not just any true narrative sentence will serve to express a historical proposition. Historical knowledge is knowledge of the historical significance of events. A narrative sentence expresses a historical proposition if, and only if, it displays the historical significance of the event it

\footnotetext{
${ }^{17}$ Lydia Goehr makes much of the importance of this point for Danto’s arguments. See Goehr 'Afterwords: An Introduction to Arthur Danto's Narration and Knowledge (including his Analytical Philosophy of History), in Danto, Narration and Knowledge. But because Danto's concern is historical knowledge and historical representation, he needs to claim that his first argument applies to propositions as well as to sentences, and that is a distinct point.

${ }^{18}$ Danto, Narration and Knowledge, p. 180.
} 
is about. And it does this if, and only if, it relates the event in question to an event in its future in which historians of the future are interested, in their capacity as historians. To return to our example (see §2): Thatcher's decision to withdraw the Endurance no doubt bears relations to a whole host of future events. A narrative sentence that records one of those relations may not express a historical proposition. But we might think the narrative sentence with which we are concerned - viz. 'Thatcher's decision to withdraw the Endurance precipitated the Argentine invasion' - expresses such a proposition, precisely because that invasion is an event in which many historians of the future are interested, in their official capacity.

But who are these historians? For all Danto says, it might be that an event counts as one in which historians of the future are suitably interested if, and only if, it suitably interests the majority of historians in existence from the point at which the event occurs until the end of history. But then we cannot know the historical significance of an event until we know how things stand at the end of history. And that cannot be Danto's view, because he thinks historical knowledge is in our grasp, even though knowledge of the future is not (see §5). So, perhaps his thought is that the event counts as one in which historians of the future are interested if, and only if, it suitably interests the majority of historians in existence from the point at which the event occurs until now. That thought ensures there is a hidden parameter in historical knowledge. Historical knowledge is knowledge of the historical significance that an event has at a certain point in time. At a certain point in time, an event has historical significance. But as time goes on, and historians' interest fades, so does its significance. An event that was once the object of historical knowledge is no longer, not because historians' beliefs about the event's relations to other events are now false, but because the majority of historians are no longer interested in these other events (in their official capacity).

Let us assume this is what Danto has in mind. His argument can now proceed as follows. If we have historical foreknowledge, we know what future historians will know about what happens to us. But if we know what future historians will believe about what happens to us, we can easily falsify their beliefs about what happens to us. And if we can easily falsify their beliefs about what happens to us, they do not know what happens to 
us. And so we do not have historical foreknowledge. Historical foreknowledge is selfdefeating.

This obscure argument seems to fall at the first premise. To have historical knowledge of events in our future all we need to know is (a) to what events in their future they are related, and (b) in what events in their future to which they are related historians in their future are interested. But it does not follow that we need to know about the knowledge of future historians. So long as we have knowledge of (a) and (b), it does not matter if future historians are wholly ignorant of the relations between these events.

It is possible to reconstruct Danto's argument so that it does not face this hurdle. But when we do so we will see that his argument is wholly independent of his conception of historical significance. The argument would go through even if historical foreknowledge amounted simply to knowledge of (a).

The reconstructed argument runs as follows. We can easily falsify beliefs about what happens in the future. ${ }^{19}$ So, we do not have knowledge of what happens in the future. But we have historical foreknowledge only if we have knowledge of what happens in the future. Therefore, we do not have historical foreknowledge.

It seems that by 'we' Danto means each of us - each human being, or even each rational subject. The argument is evidently unsound, because there are evidently some beliefs that I have about what happens in the future that I cannot falsify. But we can further reconstruct the argument so that it avoids this difficulty, as follows. We can easily falsify some of our beliefs about what happens in the future. So, some of our beliefs about what happens in the future do not constitute knowledge about what happens in the future. Therefore, some of our beliefs about what happens in the future do not constitute historical foreknowledge.

It seems to me plausible that this argument is sound. But something needs to be said in defence of the inferential step from its first premise to its interim conclusion.

The thought underlying this step might be put as follows. If someone believes that a certain event will not occur until a certain point in time, and it is in my power to bring this event about whenever I wish, I can ensure that the event occurs at some earlier point in time, and thereby ensure that the person's belief is false. Of course, if I do

\footnotetext{
${ }^{19}$ That may include historians' starting to be interested in various events. But it needs not do so.
} 
falsify his belief in this way, his belief does not constitute knowledge. But even if I do not falsify his belief in this way, and even his belief is true, the fact that I am able easily to falsify his belief ensures that his belief does not constitute knowledge.

The correctness of this last claim turns on how we are to understand the idea of a belief that I am able easily to falsify. It is a platitude of contemporary epistemology that if a belief constitutes knowledge, then it could not easily be false. ${ }^{20}$ But a true belief I am able easily to falsify is a belief that could easily be false. Exactly how we are to flesh out the idea expressed by the phrase 'could not easily be false' is a matter of debate, of course. ${ }^{21}$ But it is surely plausible to suppose that, if I am not merely able to falsify the aforementioned belief by ensuring that the relevant event does not happen, but fully intend to do so, and yet not do so because I am momentarily distracted, then although the belief is true, it could easily be false, and so does not constitute knowledge.

The soundness of the argument should now be plausible. It is plausible to think there are some propositions about the future that we cannot know. The exact scope of these propositions is not an issue I need to enter here. But it is unlikely to be especially broad. So, for all Danto's second argument can mandate, there may events in the future of which we have historical foreknowledge. At best, Danto's argument exposes, not the impossibility, but the limits of the substantive philosophy of history.

7. Danto does not establish the impossibility of historical foreknowledge. But he may, plausibly, be thought to have shown that there is a limit to what a substantive philosophy of history can achieve. And, in the course of so doing, he succeeds in shedding light on that under-appreciated feature of human agency signalled by the fact that many of the sentences we use to describe action are in the progressive tense.

Of course, Danto wants to do more than this. He wants to close down the substantive philosophy of history, twice over in fact. And he wants to do so, on each occasion, with no more than an a priori argument. But it seems to me that a better way to

\footnotetext{
${ }^{20}$ To pick an example at random: see Timothy Williamson, Knowledge and its Limits (Oxford: Oxford University Press, 2000).

${ }^{21}$ For a recent attempt to flesh out this idea, see Duncan Pritchard, Epistemic Luck (Oxford: Oxford University Press, 2005).
} 
tackle claims of such extraordinary epistemological immodesty as claims to historical foreknowledge is to ask what possible basis their proponents could have for their claims, and then to consider, and if possible reject, suitable candidates for this basis. That would no doubt be a piecemeal, case-by-case affair. In attempting to establish its impossibility in one fell swoop, Danto proves to be almost as immodest as the philosophy against which he quite reasonably inveighs. 